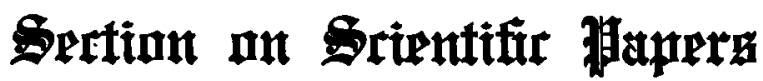

\author{
Papers Presented at the Sixtieth Annual Convention
}

\section{THE PRODUCTION AND VALUATION OF BELLADONNA IN MINNEAPOLIS.}

MANLY H. HAYNES, PHM. B., AND E. L. NEWCOMB, P. D., MINNEAPOLIS, MINN.

Recent discussions on the advisability of admitting the entire plant of Atropa Belladonna into the Pharmacopoeia to represent the drugs Belladonnae Radix and Belladonnae Folia make it important to investigate carefully the production of this drug and the valuation of the various parts of the plant.

Belladonnae Folia and Belladonnae Radix are derived mostly at the present time from cultivated plants and, although the methods of cultivation are no doubt well understood by those who grow the plants commercially, it may be of interest and some value to give the methods used and observations recorded in research along this line carried on at the medicinal plant garden of the College of Pharmacy of the University of Minnesota.

Many investigators have reported difficulty in germinating the seed of Atropa Belladonna and some even consider that it is much easier and more economical to propagate by means of root-cuttings. Propagation by means of root-cuttings is essential in the work of the plant breeder to enable liim to directly develop plants which possess the desired characteristics. Propagation from seed, however, is the method more frequently employed, as this yields a much larger number of plants in a given time. When the desired strains have been produced by plant breeding and are fairly well established, then propagation from the seeds of those strains may be carried on, provided proper care is taken to prevent reversion.

Borneman ${ }^{1}$, it appears, succeeded best when he planted the seeds under a cold cover in the early part of April, for he thus secured germination of seventy-five percent. Twenty-five percent of these seedlings, however, were lost when transplanted to the open field.

Schneider ${ }^{2}$, in a rather lengthy article, discussed seeding in cold frames and in the open and reported very satisfactory results in growing plants in a cold frame. Field sowing, however, was not satisfactory as the seeds require some time to germinate and are liable to be smothered out by weeds or hindered in their growth by the surface soil becoming packed. In connection with this work a number of methods were tried to shorten the time of germination, but these were for the most part without success.

Culture Experiments at Minneapolis.-At the College of Pharmacy of the University of Minnesota, a large number of plantings were made under varying 
conditions, but as yet no way has been found to materially shorten the period of germination. It has been noted, however, that in nearly every planting test a small percent of the seed would germinate in from two to three weeks, the remainder requiring four to five weeks when kept moist and at a temperature of from fifty to sixty degrees Fahrenheit. Three percent of one lot that was placed over hot water pipes germinated in eight days while the remaining seeds that germinated required five weeks. A similar variation has been noted in the time required for germination of seeds of a number of other drug plants. This indicates the need of study of the germinating qualities of seed from fruit collected at different stages of maturity. Various temperatures have been tried here to hasten the germination, but with indifferent success. Home-grown seed germinated about one week earlier, under the same conditions, than imported seed. (This is also the experience of Schneider). The young plants are rather tender after a rapid, forced growth at warm temperature and a large percentage usually die if planted in the open. However, by watering the young seedlings sparingly and increasing their exposure, their growth is somewhat stunted, but they thus become very hardy and stand transplanting in the open with very little loss. Wellrooted plants germinated under these conditions were placed out into the open drug garden about June 1, and after they became well rooted in the open field, they withstood a great deal of dry weather, probably because of the reserve in the starchy roots. The amount of foliage produced during such periods was much less than when the plants were abundantly watered. Some of the plants were retarded in their growth by the attack of green aphis and white fly. Whale oil soap and tobacco water proved efficient in eradicating these insects and the plants soon recovered.

Practically every sample of seed tested yielded in time a large percent of plants, although some of the seed was known to be several years old. The results would indicate that the seed of Atropa Belladonna retains its vitality for a long time. The germinating period, however, does not seem to materially increase with the age of the seed.

Under normal conditions of temperature, the young seedlings if provided with abundant water and good drainage grow quite rapidly and are usually sufficiently large for field planting within eight weeks.

While it is generally considered that Atropa Belladonna will not survive winters where the temperature drops to ten degrees Fahrenheit, it is interesting to note that during the winter of 1910-11, one of a number of plants purchased in Philadelphia and planted in the drug garden of the College of Pharmacy of the University of Minnesota where the experiments recorded in this paper were carried on, in the fall of 1910 lived outside through the winter during which the temperature went as low as twenty-five degrees below zero (Fahrenheit). During the past winter (1911-12) two plants, which made a very strong growth from seedlings planted the spring before, were protected with only a small amount of litter, but survived through a temperature of thirty-three degrees below zero (Fahrenheit). Five seedlings which were not planted out in the open but hardened by being kept in a confined and protected area in the slat-house also survived the winter. While these observations do not warrant any attempt to com- 
mercially winter over Belladonna in this region, they indicate that it may be possible by selection to develop perfectly hardy strains of Atropa Belladonna for sections of the country where the temperature is much lower than ten degrees Fahrenheit. Of course it must be borne in mind that in breeding hardy strains a sacrifice must not be made for plants of low alkaloidal value. This phase of the subject will be discussed in a later part of this paper.

In order to develop the most thrifty plants possible the plots devoted to their culture were watered frequently and with this treatment the plants made a very rapid growth. The soil of one plot consisted of a light sandy loam mixed with about six inches of well-rotted peat, which latter had been on the ground for a number of years. The character of this soil being somewhat different from that in which most other investigators have grown the plant, results different from theirs were to be expected. The difference was particularly noted in the root system, there having been developed a large number of fine rootlets while the main tap roots were only of average size. A second plot in which the soil consisted of a rich sandy garden loam produced plants having very thick and long tap roots, many from five to six centimeters in diameter at the crown and thirty to fifty centimeters in length. Only a few fine rootlets were produced by the plants in this second plot.

The overground portions of the plants growing in the sand and peat soil plot made an average growth in height of one meter and produced but one main overground stalk, excepting a few in which the overground stalk was injured by cutworms when the plant was first set out. These few latter plants produced from three to six somewhat shorter and smaller stalks. The plants in the rich garden loam produced one overground stalk each of an average height of 1.2 meters. These latter plants were more vigorous and produced heavier foliage. The average weight of the entire fresh plants from the sandy peat plot was four hundred forty grammes, while the average weight of those from the garden soil was six hundred sixty grammes. All the plants under observation corresponded botanically to what is known as Atropa Belladonna and only slight differences were noted in a few of the plants. Possibly these differences may prove indicators of certain physiological varieties. I regret that I did not record them at the time. The possibilities of developing such strains have been well indicated by Tschirch ${ }^{3}$ and True ${ }^{4}$. The development of strains of plants especially valuable for their medicinal qualities is of importance to those who will handle vegetable drugs in the future. No two plants are identical, although they may correspond so closely that they are classed in the same genera and species or even botanical varieties. This individuality is entirely a separate study from that involving the effects of various ecological conditions upon the constituents of plants. The development of the desired individual qualities, with the elimination of the undesired, into permanent traits of character is deserving of careful study. By the application of the law of Mendel, it has been shown that certain desired morphological characters may be reproduced with some degree of certainty in the third generation and we have every reason to believe that with such a variation there will be not only a change in the form of the plant, but also in the constituents. In other words, the possibility of producing by plant breeding, for example Belladonna, 
with a uniform but large amount of mydriatic alkaloids, is promising. On the other hand, it has been shown that plants of very closely related species cling to their individual characteristics with great tenacity. It has been shown by foreign workers that scions of a non-HCN rosaceous plant when grafted upon the root-stalk of a species of the same family yielding a large amount of $\mathrm{HCN}$, made a vigorous growth but developed none of the cyanogenetic glucosides, the rootstalk supplying the nutrition for the growth of the grafts in the usual manner, but not causing any change in the chemical composition. Thus it would seem that the work is not without some perplexing problems.

Histology.-Transverse sections were made from the roots of twenty separate plants grown in the drug garden and these all corresponded to typical Atropa Belladonna roots, showing trachæa with bordered pores, spheroids of calcium oxalate and the characteristic starch grains and the typical structure of Belladonna. Very few fibers were present. No raphides of calcium oxalate were found. Sections were also made of a large number of leaves and these conformed histologically to the type specimens of Belladonna.

Assays.-The following assays were made from drugs collected from the various plants as indicated:

On September 8 the first-year plants were flowering and fruiting abundantly and at this time twenty plants from the sand-peat soil plot were taken up and the roots separated and dried in a large drying oven at a temperature of about $90^{\circ} \mathrm{C}$. The leaves and tops were air dried in the laboratory.

Seven or eight plants were cut off at the ground and air dried in the laboratory. These were then separated into two portions. The first, Sample A1, which consisted of the tops and small stems under five millimeters in diameter, fresh, assayed 0.4046 and 0.3931 percent, respectively, being above the U. S. Pharmacopœial requirement of 0.30 percent. Sample A2, which consisted of stems over five millimeters in diameter, fresh, assayed 0.37 and 0.37 percent. The roots from one plant below the crown yielded 0.2691 and 0.2601 percent of alkaloids. One sample consisting of roots deprived of crown and rootlets and representing the roots from several plants yielded 0.42 and 0.42 percent of alkaloids. The small rootlets, which were easily detached from the roots after drying, were reserved separately for assay and yielded 0.6027 and 0.6256 percent. One whole plant consisting of leaves, stems, fruits, flowers, roots and rootlets yielded when assayed 0.261 and 0.266 percent of alkaloids.

The young white shoots from fourteen plants which were being wintered over in a root cellar were collected from the plants and dried. These sprouts lost 95.5 percent of moisture upon drying and assaved 0.688 percent of alkaloids. The plants growing in the rich garden loam were not disturbed until spring when upon assay the root of one plant gave a valuation of 0.345 percent of alkaloids.

The results of various investigators have shown more or less variation of the alkaloidal content of Atropa Belladonna grown under different conditions. Rippetoe ${ }^{5}$, on working with leaves obtained from plants cultivated in the Shenandoah Valley, found that leaves collected from plants in September assayed 0.32 percent. The seed for these plants was sown in January of the same year and transplanted several times before being set out in the open. About 66 percent of 
the plants survived the winter and leaves collected from the plants the following July assayed 0.68 percent. Leaves collected from the plants in October yielded 0.48 percent and the roots collected in the some month assayed 0.38 percent.

Experiments ${ }^{8}$ carried on in the garden of medicinal plants in Golden Gate Park, San Francisco, on a "made soil" consisting of sand and dirt hauled in, showed the climate to be well adapted to the culture of Belladonna. The leaves and stems of the third and fourth years' growth showed an alkaloidal content of from 0.4 to 0.8 percent of alkaloids; the stem alone gave an alkaloidal value of 0.5 percent. Results obtained in this laboratory show that stems of a diameter larger than five millimeters do not show as high an alkaloidal value as the smaller stems. The results obtained on the assay of an entire plant grown in the sandpeat plot are relatively low, owing partly to the amount of large stems present. A closer observation of the results indicates considerable variation in different plants. The root and tops, exclusive of large stems, when assayed appeared to yield a drug of good quality.

Two very interesting points were noted; first, that the fine rootlets which are usually lost to the commercial drug showed a high alkaloidal content as previously stated, of 0.60 percent, and second, the young sprouts upon starting in the spring assayed 0.688 percent.

Rippetoe's results would tend to show that the maximun alkaloidal content is reached in the leaves about July when the content begins to decrease. Whether this alkaloid is lost in the plant processes or whether it is returned to the root is a question. If it is true that the alkaloid is returned to the root after a certain period, then plants which have been deprived of part of their leaves would yield roots low in alkaloids if collected the same season. If, however, the whole plant be collected the whole of the alkaloid is obtained, but the reduction in alkaloidal percentage, due to the presence of the large stems, would probably materially decrease the value of the drug. On the other hand, if the leaves are collected the first year and the roots allowed to remain to grow the following year and the foliage allowed to grow unmolested and to dry on the plant, the root would then probably yield a high percentage of alkaloid. In this way the crops could be gathered alternately from various plants, new plants being started each year to replace the roots used for the production of the drug.

The roots of one plant grown on the garden soil, upon which the tops were allowed to die and which had started to sprout in the spring, yielded upon assay 0.345 percent. If the root had been assayed just previously to the time of sprouting, it would probably have given a much higher result as it has before been stated that the sprouts contain a large amount of alkaloid which is derived directly from the constructive metabolism carried on by the root.

It has been indicated by Tschirch ${ }^{7}$ that under certain conditions plants may be forced to produce amounts of alkaloids far in excess of what they ordinarily produce. The production of Cinchona, containing 0.16 percent of alkaloids by the Dutch in Java is a fine example of what may be done along pharmaco-physiologic lines. Thus with Atropa Belladonna the conditions under which the plant can be forced to produce a maximum amount of alkaloid must be carefully studied. This work involves careful study of soil and climatic conditions. 
It appears from results so far obtained here that Atropa Belladonna can be successfully cultivated in Minnesota, if due care is taken in the germination of seeds and the handling of young plants. The development of perfectly hardy strains, however, is a matter which will take much experimenting and careful study. The results of this work point out a number of other lines which must be followed up before certain questions can be answered and much work will need to be done before the cultivation of Atropa Belladonna is a commercial possibility for Minnesota.

\section{REFERENCES.}

${ }^{1}$ Borneman-Amer. Journ. Pharm., 1909, Vol. 81, p. 1.

${ }^{2}$ Schneider-Proc. A. Ph. A., 1909, p. 833.

${ }^{3}$ Tschirch-Pharm. Era, November, 1911.

'True-Proc. A. Ph. A., 1909, p. 827.

${ }^{5}$ Rippetoe-Proc. A. Ph. A., 1909, p. 834.

${ }^{8}$ Schneider-Proc. A. Ph. A., 1909, p. 833.

'Tschirch-Pharm. Era, November, 1911.

The Medicinal Plant Garden of the College of Pharmacy of the University of Minnesóta, June 19, 1912.

\section{CRUDE GELSEMININE AND ITS POSSIBLE CONSTITUENTS.}

L. E. SAYRE, LAWRENCE, KANSAS.

In reports of the proceedings of this section there will be found, for several years past, a record of a continuous series of experiments, which have given a clearer conception of the nature of that uncrystallizable alkaloid, named by Thompson Gelseminine.

In the last paper, the writer reported that from this alkaloid could be extracted another which, if finally proven to exist, he would name Gelsemoidine. It was suggested that this Gelsemoidine could be separated from Gelseminine by alkaline solvents-the former being soluble, the latter insoluble in such a solution. Our work this year, upon a new lot of drug (50 pounds) has given us an opportunity to collect more of this crude alkaloid, Gelseminine and study it more thoroughly.

Fifty pounds of the drug were extracted first with Petroleum Ether, the drug dried and exhausted with 95 percent alcohol. The alcohol percolate was concentrated to soft extract in a vacuum. This soft extract was extracted with benzol (using a total of $4000 \mathrm{cc}$.) after the addition of $75 \mathrm{cc}$. 26 percent ammonia solution. The benzol extractions were washed out with 5 portions ( 300 cc. each) of 2 percent $\mathrm{H}_{2} \mathrm{SO}_{4}$. The acid solution shaken with four portions (500 cc. each) of chloroform to remove the so-called Gelsemic Acid (3.9 gm. of crude acid were recovered.)

The purified acid solution (after making alkaline) was shaken out with etherchloroform ( 5 to 1 ) using $2000 \mathrm{cc}$. in all. The filtered solution was then concentrated in vacuum to small volume and set aside. Crystals of Gelsemine Hydrochloride $(5.6 \mathrm{gm}$.) were deposited. The supernatant liquid would not crystallize on further concentration, but left a gummy mass (13 gm.) of Thompson's Gelseminine hydrochloride. 